\title{
Development of Deep-Sea Resonant Sandwich Linear Ultrasonic Motor
}

\author{
Shaopeng He, Shengjun Shi, Weishan Chen \\ State Key Laboratory of Robotics and System, Harbin Institute of Technology, Harbin, China \\ Email: hsp@stu.hit.edu.cn
}

How to cite this paper: He, S.P., Shi, S.J. and Chen, W.S. (2018) Development of Deep-Sea Resonant Sandwich Linear Ultrasonic Motor. Journal of Applied Mathematics and Physics, 6, 296-300. https://doi.org/10.4236/jamp.2018.61028

Received: January 3, 2018

Accepted: January 28, 2018

Published: January 31, 2018

\begin{abstract}
A deep-sea resonant sandwich linear ultrasonic motor is proposed and designed. We determine the parameter of its structure by finite-element analysis. The piezoelectric actuator adopts compound vibration mode of fifth order bending vibration and second order longitudinal. The mode degeneracy of that is completed. We manufacture the prototype to measure the performance of it. We measure its vibration mode and resonant frequency. The velocity of prototype can reach $264.5 \mathrm{~mm} / \mathrm{s}$ while the water pressure is $8 \mathrm{MPa}$ and the voltage signal with frequency of $30.30 \mathrm{kHz}$ and voltage amplitude of $150 \mathrm{~V}$.
\end{abstract}

\section{Keywords}

Piezoelectric Actuator, Finite-Element Analysis, Hybrid Mode, Fluid-Solid Coupling

\section{Introduction}

Piezoelectric actuator is a kind of new motor which using inverse piezoelectric effect of piezoelectric ceramics [1] [2] [3]. Piezoelectric actuators have advantages of compact structure, high power with small weight, without electromagnetic interference and self-locking by frictional. Piezoelectric actuators are classified into two types: single vibration mode and compound vibration mode [3] [4] [5]. Piezoelectric actuators of compound vibration mode have higher performance than single vibration mode. At present, piezoelectric actuators have been studied by researchers, and they have been applied into many fields of spaceflight, automation and so on [6] [7] [8] [9]. We study the compound vibration mode piezoelectric motor working in deep-sea environment.

In this study, we design a deep-sea resonant sandwich linear ultrasonic motor and manufacture the prototype to measure its performance. The piezoelectric actuator adopts compound vibration mode of fifth order bending vibration and 
second order longitudinal. We complete the mode degeneracy by finite element analysis. We design and set up the experimental platform to measure the performance of prototype. The velocity of prototype can reach $264.5 \mathrm{~mm} / \mathrm{s}$ while the water pressure is $8 \mathrm{MPa}$ and the voltage signal with frequency of $30.30 \mathrm{kHz}$ and voltage amplitude of $150 \mathrm{~V}$. It verifies the simulation result and reaches the experiment objective.

\section{Finite Element Analysis}

We select a configuration to build finite element model as show in Figure 1. This configuration adopts compound vibration mode of five order bending vibration and second order longitudinal vibration. High order bending vibrations and longitudinal vibrations are small affected by deep-sea environment. We complete the mode degeneracy by adjust the parameter of piezoelectric actuator. We obtain the sensitivity of main parameters about resonant frequency as shown in Figure 2. We determine the final parameters of structure as show in Table 1.

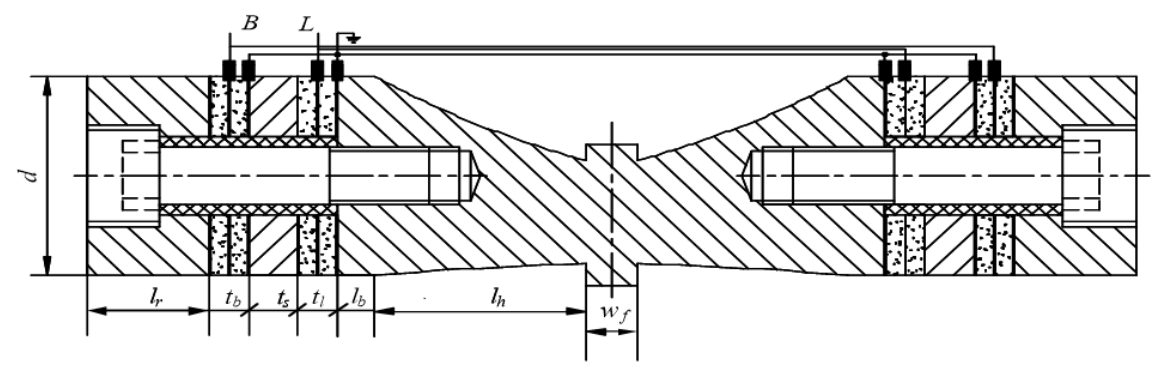

Figure 1. Structure of piezoelectric actuator.
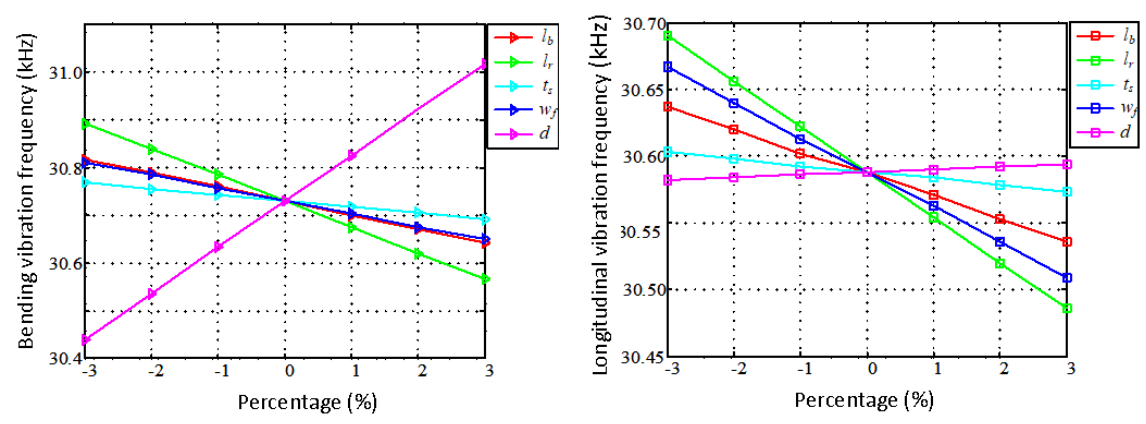

Figure 2. Sensitivity of main parameters.

Table 1. Parameter of structure.

\begin{tabular}{cccccccc}
\hline$d$ & $l_{\mathrm{r}}$ & $t_{\mathrm{b}}$ & $t_{1}$ & $t_{\mathrm{s}}$ & $w_{\mathrm{f}}$ & $l_{\mathrm{h}}$ & $l_{\mathrm{b}}$ \\
\hline 35 & 20 & 6 & 6 & 8 & 8.5 & 37.5 & 6 \\
\hline
\end{tabular}

After it, the finite element model under water is built to obtain the resonant frequency as shown in Figure 3. We compare the resonant frequency under water with normal resonant frequency, as shown in Table 2. It shows water have stronger effect on five order bending vibration than second order longitudinal 
vibration. We also get many resonant frequencies with different pressure of water as shown in Table 3. It shows the pressure almost has no effect on resonant frequency. Finally, we conduct transient analysis to verify feasibility of this piezoelectric actuator.
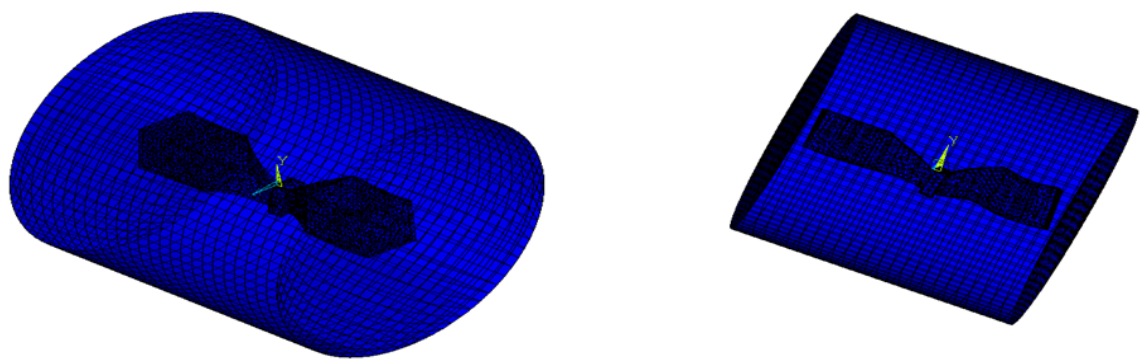

Figure 3. Finite element model.

Table 2. Resonant frequency with different environment.

\begin{tabular}{cccc}
\hline & $\begin{array}{c}\text { Resonant frequency } \\
\text { in air }\end{array}$ & $\begin{array}{c}\text { Resonant frequency in } \\
\text { water }\end{array}$ & Differentials \\
\hline $\begin{array}{c}\text { bending vibration } \\
(\mathrm{kHz})\end{array}$ & 30.730 & 30.214 & 0.516 \\
$\begin{array}{c}\text { longitudinal } \\
\text { vibration }(\mathrm{kHz})\end{array}$ & 30.588 & 30.478 & 0.110 \\
\hline
\end{tabular}

Table 3. Resonant frequency with different pressure.

\begin{tabular}{ccccccc}
\hline pressure (Mpa) & 2 & 4 & 8 & 12 & 16 & 20 \\
\hline $\begin{array}{c}\text { bending vibration } \\
(\mathrm{kHz})\end{array}$ & 30.201 & 30.178 & 30.156 & 30.132 & 30.109 & 30.088 \\
$\begin{array}{c}\text { longitudinal } \\
\text { vibration }(\mathrm{kHz})\end{array}$ & 30.474 & 30.470 & 30.464 & 30.456 & 30.450 & 30.445 \\
\hline
\end{tabular}

\section{Experimental Study}

We manufacture the prototype to measure the performance of this piezoelectric actuator, as shown in Figure 4. After it, we used the scanning laser Doppler vibrometer (PSV-400-M2, Polytec, Germany) to measure its vibration mode and the resonant frequency, as shown in the Figure 5 and Figure $\mathbf{6}$. We can know the vibration mode and the resonant frequency is almost coincident with the simulation. We think the fabrication error contribute on the little different.

When the prototype is placed in the deep sea high pressure simulation system, we use precision impedance analyzer to measure impedance characteristic of prototype and obtain the resonant frequency, as shown in Figure 6. It has a little reducing compare with the normal environment, which shows correspondence with simulation result. Finally, the velocity of prototype reaches $264.5 \mathrm{~mm} / \mathrm{s}$ while the water pressure is $8 \mathrm{MPa}$ and the voltage signal with frequency of 30.30 $\mathrm{kHz}$ and voltage amplitude of $150 \mathrm{~V}$. 

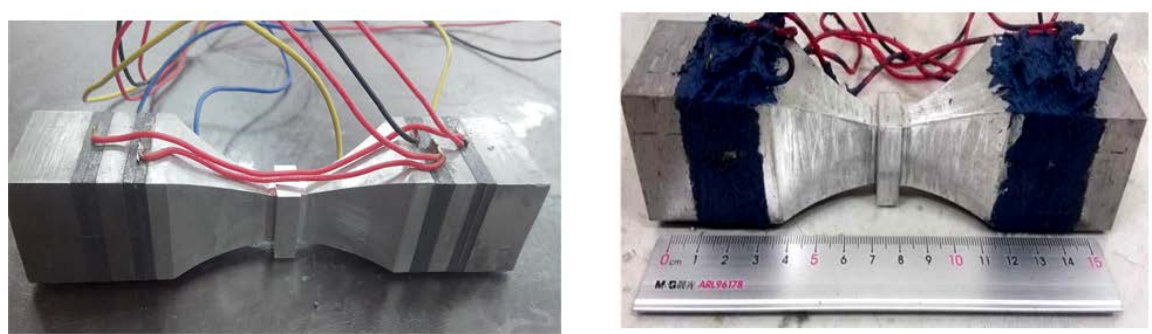

Figure 4. Prototype and sealed prototype.
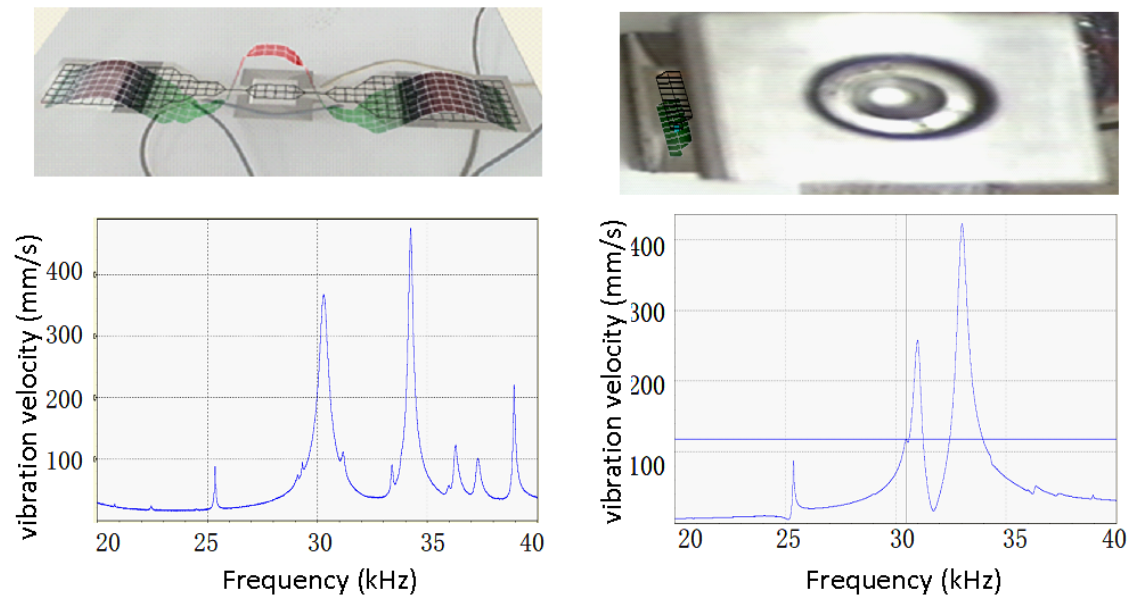

Figure 5. Vibration mode and vibration velocity of prototype.
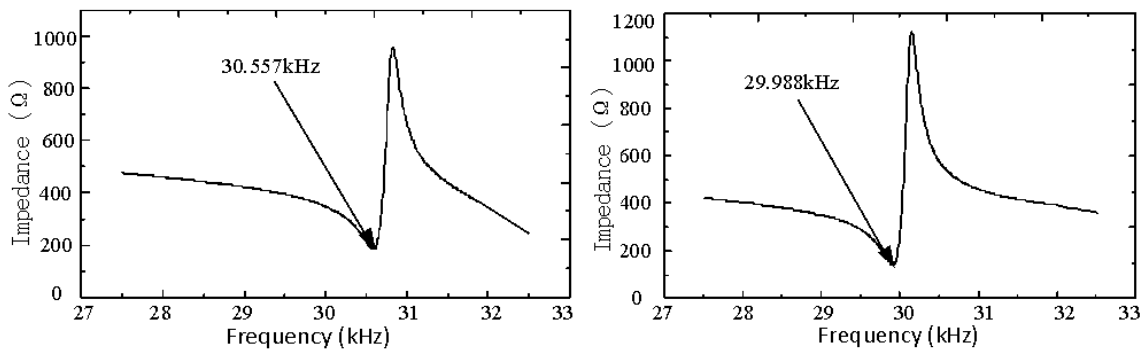

Figure 6. Impedance analysis result.

\section{Conclusion}

In this study, we design and study a deep-sea resonant sandwich linear piezoelectric actuator. We complete the mode degeneracy of fifth order bending vibration and second order longitudinal vibration. We manufacture the prototype and measure its performance. The measuring result verifies the simulation result. Finally, prototype's velocity reaches $264.5 \mathrm{~mm} / \mathrm{s}$ while the water pressure is $8 \mathrm{MPa}$ and the voltage signal with frequency of $30.30 \mathrm{kHz}$ and voltage amplitude of $150 \mathrm{~V}$.

\section{Acknowledgements}

This project is supported by the National Natural Science Foundation of China (No. 51575124). 


\section{References}

[1] Smithmaitrie, P., Suybangdum, P., Laoratanakul, P. and Muensit, N. (2012) Design and Performance Testing of an Ultrasonic Linear Motor with Dual Piezoelectric Actuators. IEEE Transactions on Ultrasonics, Ferroelectrics and Frequency Control, 2012. https://doi.org/10.1109/TUFFC.2012.2289

[2] Zhakypov, Z., Golubovic, E., Uzunovic, T. and Sabanovic, A. (2013) Piezoelectric Motor Driver: Design and Evaluation. IEEE Control Conference, 2013.

[3] Vyshnevsky, O., Kovalev, S. and Wischnewskiy, W. (2005) A Novel, Single-Mode Piezoceramic Plate Actuator for Ultrasonic Linear Motors. IEEE Transactions on Ultrasonics, Ferroelectrics, and Frequency Control, 52, 2047-2053. https://doi.org/10.1109/TUFFC.2005.1561674

[4] Yokoyama, K., Tamura, H. and Masuda, K. (2013) Single-Phase Drive Ultrasonic Linear Motor Using a Linked Twin Square Plate Vibrator. Japanese Journal of Applied Physics, 52, 07HE03. https://doi.org/10.7567/JJAP.52.07HE03

[5] Spanner, K. and Koc, B. (2016) Piezoelectric Motors, an Overview. Actuators, 5, No. 1. https://doi.org/10.3390/act5010006

[6] Shi, Y.L., Li, Y.B. and Zhao, C.S. (2011) A New Type Butterfly-Shaped Transducer Linear Ultrasonic Motor. Journal of Intelligent Material Systems and Structures, 2011, 1045389X11404955.

[7] Shi, Y.L., Zhao, C.S. and Huang, W.Q. (2010) Linear Ultrasonic Motor with Wheel-Shaped Stator. Sensors and Actuators A: Physical, 161, 205-209. https://doi.org/10.1016/j.sna.2010.05.009

[8] Cheol-Ho, Y., Ishii, T. and Nakamura, K. (2001) A High Power Ultrasonic Linear Motor Using a Longitudinal and Bending Hybrid Bolt-Clamped Langevin Type Transducer. Japanese Journal of Applied Physics, 40, 3773. https://doi.org/10.1143/JJAP.40.3773

[9] Asumi, K., Fukunaga, R. and Fujimura, T. (2009) High Speed, High Resolution Ultrasonic Linear Motor Using V-Shape Two Bolt-Clamped Langevin-Type Transducers. Acoustical Science and Technology, 30, 180-186.

https://doi.org/10.1250/ast.30.180 